\title{
Research of the Effect of Modification on the Structure and Properties of Castings from Steel H11 Obtained by Using Electrosfining Technology
}

\author{
Natalia V. Larionova, Alexander M. Tokmin, \\ Vladimir S. Kazakov* and Oleg A. Masansky \\ Siberian Federal University \\ 79 Svobodny, Krasnoyarsk, 660041, Russia
}

The methods of increasing the disequilibrium of the system due to the modification, castings of alloy steel, obtained by electroslag chill casting are considered. The microstructures of the castings are shown and the results of tests to determine the mechanical properties of the samples obtained under various technological regimes of the electroslag technology are presented.

Keywords: modification, crystallization, die steel, electroslag chill casting.

Citation: Larionova N.V., Tokmin A.M., Kazakov V.S., Masansky O.A. Research of the effect of modification on the structure and properties of castings from steel H11 obtained by using electrosfining technology, J. Sib. Fed. Univ. Eng. technol., 2019, 12(5), 599-606. DOI: 10.17516/1999-494X-0159.

\section{Исследование влияния модифицирования на строение и свойства отливок из стали 4Х5МФС,} полученных с применением электрошлаковой технологии

\author{
Н.В. Ларионова, А.М. Токмин, \\ В.С. Казаков, О.А. Масанский \\ Сибирский федеральный университет \\ Россия, 660041, Красноярск, пр. Свободный, 79
}

Рассмотрены методы повышения неравновесности системы за счет модифицирования отливок из легированной стали, полученных электрошлаковым кокильныл литьем. Показаны микроструктуры отливок и представлены результаты испытаний по определению

(C) Siberian Federal University. All rights reserved

This work is licensed under a Creative Commons Attribution-NonCommercial 4.0 International License (CC BY-NC 4.0)

* Corresponding author E-mail address: vskazakov@yandex.ru 
механических свойств образцов, полученных при различных технологических режимах электрошлаковой технологии.

Ключевые слова: модифицирование, кристаллизация, итамповая сталь, электрошлаковое кокильное литье.

\section{Введение}

В настоящее время все большее внимание уделяется выявлению взаимосвязей между составом, строением и свойствами сплавов, получаемых в неравновесных условиях, за счет применения технологий, позволяющих оказывать многофакторное воздействие в процессе плавления, кристаллизации, последующего охлаждения и термической обработки. Это может обеспечить управление структурообразованием в расплавах и сплавах в условиях, далеких от термодинамического равновесия.

Оптимизация физико-химических процессов получения сплавов в неравновесных условиях, которые определяются параметрами, формирующими степень неустойчивости системы, является существенным резервом в получении заданного фазового состава и структурного состояния сплавов.

\section{Технология получения отливок}

В данной работе рассмотрены методы повышения неравновесности системы за счет модифицирования отливок, полученных в условиях электрошлаковой технологии.

Для реализации электрошлакового литья в кокиль применялся комплекс оборудования. В данном случае в его состав входит установка с трансформатором А622M, подвижный тигель и технологическая оснастка: кокиль, электрододержатель и расходуемый электрод. Это оборудование предназначено для получения жидкого металла аналогичного химического состава, что и расходуемый электрод, накопления его в плавильной емкости с последующим переливом в литейную форму-кокиль требуемой конфигурации.

Электрошлаковый переплав электрода, изготовленного, как правило, из отбракованных поковок соответствующих марок сталей, осуществляется на переменном токе. Расходуемый электрод опускали до соприкосновения с затравкой, которая изготавливается из смеси металлической стружки соответствующего состава и флюса в определенной пропорции. В пространство между электродом и стенкой рабочей зоны засыпали предварительно прокаленный в течение двух часов флюс АНФ-295, процесс выполняли на сухом старте.

После включения напряжения (табл. 1) через 5-7 мин флюс расплавляется, образуя жидкую шлаковую ванну, и начинается процесс переплава электрода.

Таблица 1. Режимы электрошлакового переплава

Table 1. Electroslagremeltingmodes

\begin{tabular}{|c|c|c|c|c|c|}
\hline \multirow{2}{*}{ Вид переплава } & \multicolumn{2}{|c|}{ Начало плавки } & \multicolumn{2}{|c|}{ Конец плавки } & Раскисление \\
\cline { 2 - 7 } & $\mathrm{I}, \mathrm{\kappa A}$ & $\mathrm{U}, \mathrm{B}$ & $\mathrm{I}$, кA & $\mathrm{U}, \mathrm{B}$ & $\mathrm{Al}, \%$ \\
\hline Электрошлаковое кокильное литье (ЭКЛ) & 2,5 & 50 & 2,5 & 50 & 0,2 \\
\hline
\end{tabular}




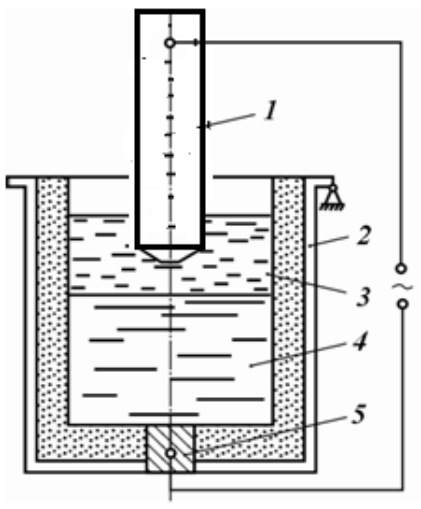

a

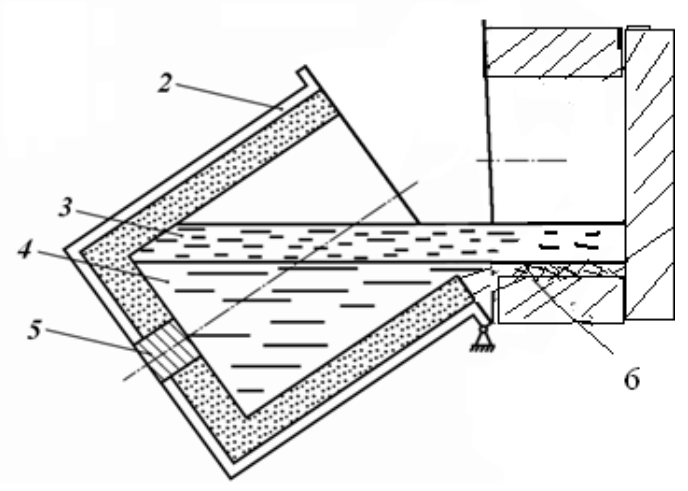

б

Рис. 1. Схема получения металла в электрошлаковых тигельных печах: $a$ - получение жидкого металла; $\sigma$ - схема заливки металла в форму: 1 - расходуемый электрод; 2 - плавильный тигель; 3 - жидкий шлак; 4 - расплавленный металл; 5 - донный электрод; 6 - литейная форма

Fig. 1. Scheme of obtaining metal in electroslag crucible furnaces: $a$-production of liquid metal; $\sigma$ - metal pouring into the mold: 1 -consumable electrode; 2 -melting crucible; 3 - liquid slag; 4 -molten metal; 5 -bottom electrode; 6 - casting mold

Установка (рис. 1) предназначена для крепления переплавляемого электрода и перемещения его в вертикальном направлении. Ее питание осуществляется от трансформатора А622H, который рассчитан на ток 10 кА при однофазном подключении. Первичное напряжение составляет 380 В, вторичное 40-70 В. Кабели от трансформатора до клемм электрододержателя и кабель к пластине токоподвода тигля подвижно-водоохлаждаемые. Кокиль установлен на кронштейны подвижного тигля и фиксируется крючками. Поворот тигля осуществляется с помощью мотор-редуктора и винтовой передачи.

В процессе получения отливок применяли раскисление алюминием А7 в количестве $0,2 \%$. После накопления заданного количества металла при помощи поворотного устройства тигель переворачивали, и металл переливали в кокиль, закрепленный в верхней части тигля. Температура металла перед переливом в кокиль составляла $1550-1600^{\circ} \mathrm{C}$. Отливки рассекателей весом 18-20 кг (рис. 2) извлекали из кокиля при температуре $800-700{ }^{\circ} \mathrm{C}$ и помещали в песочную ванну. Замедленное охлаждение отливок вызвано тем, что сталь 4Х5МФС относится к сталям мартенситного класса с большой устойчивостью переохлажденного аустенита. В результате охлаждения на воздухе формируется мартенситная структура и возникают большие напряжения, которые могут привести к возникновению трещин.

Известно [1], что эксплуатационные свойства во многом зависят от типа, размеров, распределения и формы неметаллических включений. Неметаллические включения оказывают влияние на структуру и химическую неоднородность сталей при кристаллизации, фазовой перекристаллизации и т.д. Кроме того, неметаллические включения существенно влияют на концентрацию напряжений при упругих деформациях, она тем больше, чем меньше модуль упругости включения. По мере уменьшения модуля упругости включения располагаются в ряд $\mathrm{TiN}, \mathrm{Al}_{2} \mathrm{O}_{3}, \mathrm{SiO}_{2},(\mathrm{Fe}, \mathrm{Mn}) \mathrm{S}, \mathrm{CaO}$ [2]. Существенную роль играет форма неметаллических включений. У включений с явно выраженной огранкой и острыми ребрами концентрация на-

$$
-601-
$$




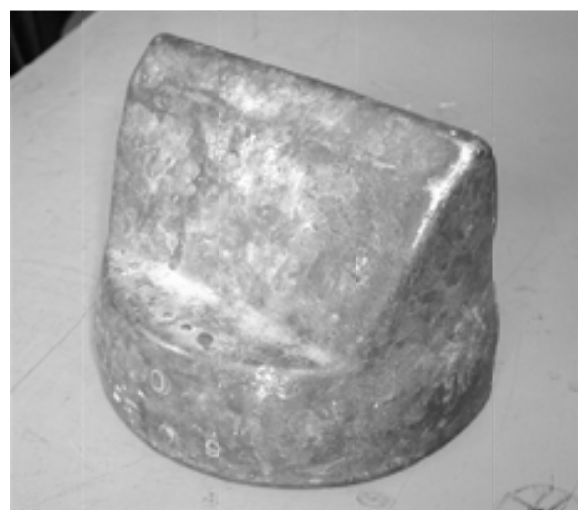

Рис. 2. Отливка рассекателя из стали 4Х5В2ФС, полученная методом ЭКЛ, ×0,25

Fig. 2. Casting divider from steel H11, obtained by electroslag chill casting method $\times 0,25$

пряжений более чем в 1,5 раза больше, чем у сферических такой же величины. Это связано с тем, что уровень интенсивности напряжений во многом определяется минимальным радиусом включения. В случае острой огранки неметаллических включений, которые имеют невысокий модуль упругости, интенсивность напряжений может резко возрастать при определенной ориентации неметаллических включений.

Формирование кристаллической структуры определяется, главным образом, процессами тепломассопереноса, протекающими в переходной зоне твердожидкого состояния, которая состоит из расплава и дендритов. Плотность неметаллических включений (n) меняется из-за их коагуляции. При диффузионном механизме наиболее вероятной является бимолекулярная коагуляция, когда скорость изменения $\mathrm{n}$ равна $\mathrm{mn}^{2}$, где $\mathrm{m}-$ коэффициент коагуляции.

Значительный резерв в повышении свойств сталей - управление количеством, морфологией и свойствами неметаллических включений посредством различных технологий выплавки. Одним из способов воздействия на природу и морфологию неметаллических включений является модифицирование.

При исследовании микроструктуры штамповой стали, полученной электрошлаковым кокильным литьем, наблюдаются крупные неметаллические включения округлой и остроугольной формы, которые ухудшают свойства стали [3]. С целью изменения природы, морфологии, уменьшения количества и размеров неметаллических включений проводилось модифицирование штамповой стали 4Х5МФС редкоземельными металлами (РЗМ) - цериевый мишметалл [4].

При определении механизма модифицирования штамповой стали мишметаллом необходимо учитывать возможность образования тугоплавких соединений между неметаллическими включениями, примесями, которые находятся в жидком металле, и вводимыми элементами. При введении РЗМ возможно образование тугоплавких соединений: сульфидов, оксисульфидов и др. Вероятность образования того или иного соединения при введении в жидкую сталь редкоземельных металлов определялась по величине изменения энергии Гиббса при протекании химических реакций с применением пакета программы HSC Chemistry. 


$$
\begin{array}{ll}
3 \mathrm{Ce}+4 \mathrm{FeS} \rightarrow \mathrm{Ce}_{3} \mathrm{~S}_{4}+4 \mathrm{Fe} & -955,982 \text { кДж/моль; } \\
2 \mathrm{Ce}+3 \mathrm{FeO} \rightarrow \mathrm{Ce}_{2} \mathrm{O}_{3}+3 \mathrm{Fe} & -855,530 \text { кДж/моль; } \\
2 \mathrm{Nd}+3 \mathrm{FeO} \rightarrow \mathrm{Nd}_{2} \mathrm{O}_{3}+3 \mathrm{Fe} & -846,049 \text { кДж/моль; } \\
2 \mathrm{La}+3 \mathrm{FeO} \rightarrow \mathrm{La}_{2} \mathrm{O}_{3}+3 \mathrm{Fe} & -830,042 \text { кДж/моль; } \\
2 \mathrm{La}+3 \mathrm{FeS} \rightarrow \mathrm{La}_{2} \mathrm{~S}_{3}+3 \mathrm{Fe} & -718,903 \text { кДж/моль; } \\
2 \mathrm{Ce}+3 \mathrm{FeS} \rightarrow \mathrm{Ce}_{2} \mathrm{~S}_{3}+3 \mathrm{Fe} & -637,079 \text { кДж/моль; } \\
2 \mathrm{Ce}+\mathrm{Cr}_{2} \mathrm{O}_{3} \rightarrow \mathrm{Ce}_{2} \mathrm{O}_{3}+2 \mathrm{Cr} & -635,370 \text { кДж/моль; } \\
2 \mathrm{Nd}+\mathrm{Cr}_{2} \mathrm{O}_{3} \rightarrow \mathrm{Nd}_{2} \mathrm{O}_{3}+2 \mathrm{Cr} & -626,546 \text { кДж/моль; } \\
2 \mathrm{Nd}+3 \mathrm{FeS} \rightarrow \mathrm{Nd}_{2} \mathrm{~S}_{3}+3 \mathrm{Fe} & -624,655 \text { кДж/моль; } \\
2 \mathrm{La}+\mathrm{Cr}_{2} \mathrm{O}_{3} \rightarrow \mathrm{La}_{2} \mathrm{O}_{3}+2 \mathrm{Cr} & -610,249 \text { кДж/моль. }
\end{array}
$$

Приведенные реакции возможны при температуре $1580-1600{ }^{\circ} \mathrm{C}$, о чем свидетельствуют результаты расчета. Как видим, в первую очередь протекают реакции между редкоземельными металлами оксидом и сульфидом железа. В результате чего образуются тугоплавкие соединения: оксиды, сульфиды редкоземельных металлов. При введении в жидкий металл модификаторов цериевой группы наблюдаем образование сложных оксисульфидов кальция, алюминия, церия, лантана. Образующиеся соединения РЗМ не смачиваются, склонны к укрупнению неметаллических включений и образованию агломератов, которые всплывают под действием гравитационных сил.

\section{Исследование влияния модифицирования}

\section{на морфологию распределения неметаллических включений}

Исследования морфологии и распределения неметаллических включений после модифицирования указывают на уменьшение их количества почти в два раза, а также уменьшение размеров и изменение формы преимущественно глобулярного вида (рис. $3 a$ )

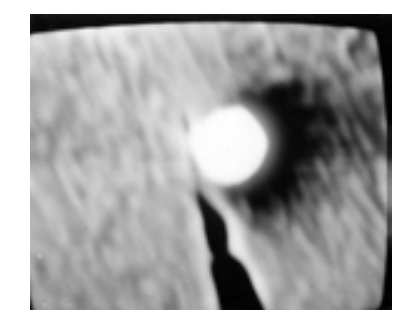

$a \times 2000$

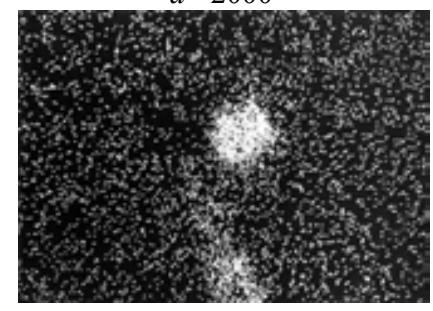

$B \times 2000$

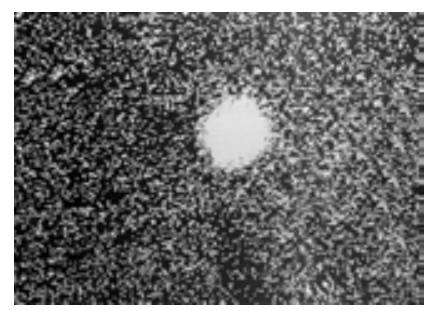

$\sigma \times 2000$

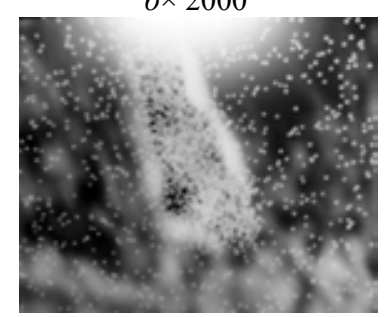

$2 \times 3100$

Рис. 3. Неметаллическое включение в характеристическом рентгеновском излучении: $a$ - форма включения; 6 - кремний; 6 - кислород; 2 - алюминий

Fig. 3. Non-metallic inclusion in characteristic X-rays: $a$-inclusion form; $\sigma-\mathrm{Si} ; 6-\mathrm{O} ; z-\mathrm{A}$

$$
-603-
$$


Исследование неметаллических включений в характеристическом рентгеновском излучении выявляет, что алюмосиликаты приобретают глобулярную форму (рис. 3б, в, г).

Следует учитывать технологию введения в расплав добавок. Алюминий и мишметалл цериевой группы вводили в виде монолитных фрагментов в расчетном количестве. Прежде чем попасть в жидкую сталь, они проходят через шлаковую ванну, протяженность которой составляет примерно 100 мм. При прохождении через жидкий шлак и попадании на поверхность металлической ванны происходило растворение алюминия в шлаке и взаимодействие его с кислородом. Гранулы модификаторов, находясь на поверхности металлической ванны и взаимодействуя со шлаком, также переходили в соответствующие соединения, тем самым их доля, попадающая в жидкий металл, существенно уменьшалась. Во время переплава жидкий шлак взаимодействует с окружающей атмосферой и сталью, что приводит к повышению в нем содержания кислорода, азота и других элементов.

Термическая обработка проходила по общепринятым режимам. Твердость после отжига отливок составляла НВ 207-228. Одной из основных задач получения качественных отливок из высоколегированных сталей является уменьшение дендритной ликвации, обусловленной значениями коэффициентов распределения легирующих элементов, величина которого меньше единицы $(K<1)$. В сталях с содержанием углерода более 0,4 \% ликвация Сr и Мо развивается в большей степени. Степень ликвации в отливках, имеющих столбчатую структуру, меньше степени ликвации, характерной для зоны равноосных кристаллов, поскольку она значительно зависит от скорости кристаллизации и формы образующихся кристаллов [5]. Формирование столбчатой структуры отливок способствует созданию минимальной химической неоднородности. Низкие значения ликвации свойственны отливкам со сплошной зоной транскристаллизации. Повышение дисперсности дендритной структуры дополнительно приводит к уменьшению сегрегации на 20-30 \%.

Важно отметить, что макроструктура отливок, полученных электрошлаковым кокильным литьем, имеет транскристаллитное строение (рис. 4), что способствует уменьшению ликвации и, как следствие, повышению физико-механических свойств.

Закалка литых заготовок выполнялась от температур на $10-15{ }^{\circ} \mathrm{C}$ ниже рекомендуемых для данной стали. После закалки сохранялась зерно, соответствующее №№ 10-9. После термообработки структура отливок сохраняет некоторую неоднородность (рис. 5).

\section{Механические свойства отливок}

Механические свойства образцов из отливок имеют значения ниже, чем из деформированного металла (табл. 2). Существенные различия наблюдаются в показаниях ударной вязкости и пластичности.

Следует отметить, что прочность, ударная вязкость и пластичность образцов без модифицирования и после модифицирования имеют существенные различия. Это указывает на воздействие используемых добавок на структуру и свойства литого металла. Представляет интерес тот факт, что теплостойкость отливок не уступает теплостойкости деформируемого металла, а прочность находится примерно на одном уровне. Свойства стали с небольшой степенью деформации имеют высокий стабильный уровень. Механические свойства отливок обладают практически одинаковыми показателями независимо от направления вырезки об- 
разцов. Это связано с общей микронеоднородностью стали, которая оказывает определяющее влияние на ее свойства.

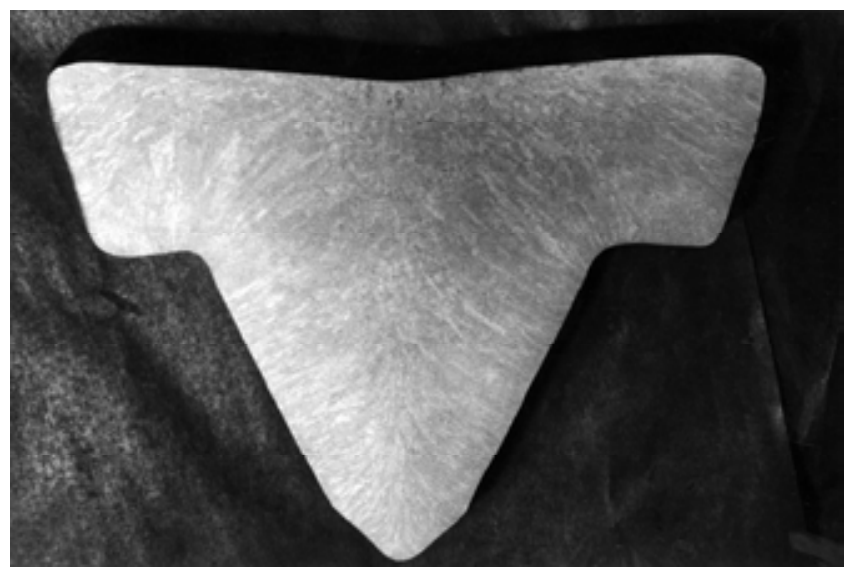

Рис. 4. Макроструктура рассекателя, имеющая транскристаллитное строение, $\times 0,5$

Fig. 4. Macrostructure divider having a transcrystalline structure, $\times 0,5$

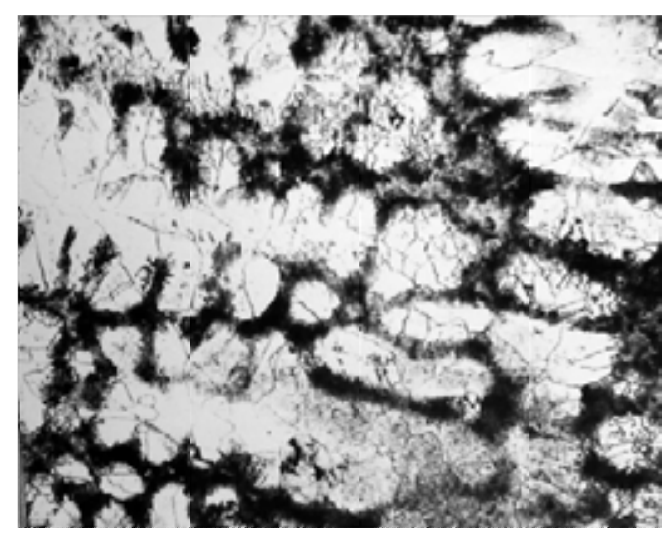

Рис. 5. Неоднородная микроструктура стали 4Х5МФС, полученной методом электрошлакового кокильного литья, $\times 100$

Fig. 5. Heterogeneous microstructure of steel H11, obtained by electroslag chill casting, $\times 100$

Таблица 2. Механические свойства сталей

Table 2. Mechanical properties of steel

\begin{tabular}{|c|l|c|c|c|c|c|c|}
\hline $\begin{array}{c}\text { № } \\
\text { п/п }\end{array}$ & \multicolumn{1}{|c|}{$\begin{array}{c}\text { Наименование } \\
\text { модификатора }\end{array}$} & Кол-во, \% & $\mathrm{HRC}$ & $\begin{array}{c}\sigma_{\mathrm{B},} \\
\mathrm{MПа}\end{array}$ & $\begin{array}{c}\sigma_{0,2}, \\
\mathrm{MПа}\end{array}$ & $\begin{array}{c}\delta, \\
\%\end{array}$ & $\begin{array}{c}\text { КСU, } \\
\mathrm{MД} / \mathrm{M}^{2}\end{array}$ \\
\hline 1 & Без модификатора & 0,2 & $45-46$ & 1322 & 1128 & 5,52 & 0,13 \\
\hline 2 & Мишметалл & 0,2 & $44-45$ & 1609 & 1367 & 9,29 & 0,28 \\
\hline 3 & Мишметалл & 0,3 & $45-47$ & 1585 & 1420 & 7,5 & 0,30 \\
\hline 4 & Кованный & $45-47$ & 1735 & 1545 & 8,0 & 0,50 \\
\hline
\end{tabular}




\section{Выводы}

1. Введение редкоземельных металлов в жидкую сталь в процессе электрошлакового кокильного литья способствует уменьшению загрязненности неметаллическими включениями.

2. В результате модифицирования наблюдается изменение морфологии, уменьшение общего количества и размеров неметаллических включений. Неметаллические включения приобретают преимущественно глобулярную форму.

3. Модифицирование мишметаллом цериевой группы в процессе ЭКЛ стали 4Х5МФС приводит к значительному повышению ударной вязкости и пластичности.

\section{Список литературы}

[1] Штремель Л.А. Проблемы металлургического качества стали (неметаллические включения), Металловедение и термическая обработка металлов, 1980, (8), 2-6 [Stremel L.A. Problems of metallurgical quality of steel (non-metallic inclusions), Metallurgy and heat treatment of metals, 1980, (8), 2-6 (in Russian)].

[2] Куслицкий А.Б. Неметаллические включения и усталость стали. Киев: Техника, 1976, 128 c. [Kuslitsky A.B. Non-metallic inclusions and steel fatigue. Kiev: Technique, 1976, 128 p. (in Russian)].

[3] Токмин А.М., Падар В.А., Ларионова Н.В. Распределение неметаллических включений при затвердевании штамповой стали в условиях электрошлаковых процессов, Технология машиностроения, 2009, (11), 5-8 [Tokmin A.M., Padar V.A., Larionova N.V. Distribution of nonmetallic inclusions during solidification of die steel in terms of electroslag processes, Mechanical Engineering Technology, 2009, (11), 5-8 (in Russian)].

[4] Лунев В.В. Теория и практика применения щелочно- и редкоземельных металлов для повышения качества стали, Новые конструкционные стали и сплавы и методы их обработки для повышения надежности и долговечности изделий: Тез. докладов IV Всесоюзной научно технической конференции. Запорожье: 1989, 195 [Lunev V.V. Theory and practice of the use of alkaline and rare earth metals to improve the quality of steel, New structural steels and alloys and methods for their processing to improve the reliability and durability of products: Tez. reports of the IV All-Union Scientific and Technical Conference. Zaporozhye: 1989, 195 (in Russian)].

[5] Голиков И.Н., Маслеников С.Б. Дендритная ликвация в сталях и сплавах, М.: Металлургия, 1977, 224 с. [Golikov I.N., Maslenikov S.B. Dendritic segregation in steels and alloys, М.: Metallurgy, 1977, 224 p. (in Russian)]. 